\title{
EFICIÊNCIA DE DOIS NOVOS TRIAZOIS ASSOCIADOS Á ADJUVANTE NO CONTROLE DA FERRUGEM DO CAFEEIRO
}

\author{
Athaise Ferreira de Lima ${ }^{1}$ \\ Tatiane Paulino $\mathrm{Cruz}^{2}$ \\ Mayse Margarida Ferreira ${ }^{3}$ \\ Mariana Duarte Silva Fonseca ${ }^{4}$ \\ Vitor Vargas Schwan ${ }^{5}$ \\ Adilson Vidal Costa ${ }^{6}$ \\ Vagner Tebaldi de Queiroz ${ }^{7}$ \\ Willian Bucker Moraes $^{8}$
}

Resumo: Objetivou-se com este trabalho determinar a eficiência das novas moléculas de triazól associadas ao adjuvante no controle de ferrugem de cafeeiro em mudas de café conilon. Os triazóis utilizados foram obtidos pela reação de Click no laboratório de fitoquímicos do NUDEMAFI (Núcleo de Desenvolvimento Científico e Tecnológico em Manejo Fitossanitário de Pragas e Doenças). Foram coletadas folhas com sinais da doença e preparada uma suspensão de $5 \times 104$ esporos $/ \mathrm{mL}$ de ferrugem, posteriormente essa suspensão foi borrifada nas mudas de cafeeiro a qual foi incubada por 48 horas em escuro, em seguida as mudas foram acondicionadas em casa de vegetação. Os triazóis foram aplicados quando apareceram os primeiros sinais da doença. Dentre as moléculas testadas neste experimento o fungicida comercial associado ao adjuvante obteve melhor os melhores resultados, o Triazol considerado com o Dez associado ao adjuvante apresentou a segunda maior Eficiência Relativa.

Palavras-chave: Hemileia vastratix; Controle químico; Coffea Canephora; Glicerol.

\footnotetext{
1 Universidade Federal do Espírito Santo, Brasil. E-mail: athaisef@hotmail.com.

2 Universidade Federal do Espírito Santo, Brasil. E-mail: agronomapaulino@hotmail.com.

3 Universidade Federal do Espírito Santo, Brasil. E-mail: mayseferreira@live.com.

${ }^{4}$ Universidade Federal do Espírito Santo, Brasil. E-mail: duarte123@hotmail.com.

${ }^{5}$ Universidade Federal do Espírito Santo, Brasil. E-mail: vitor.schwan@hotmail.com.

6 Universidade Federal do Espírito Santo, Brasil. E-mail: avcosta@hotmail.com.

7 Universidade Federal do Espírito Santo, Brasil. E-mail: vagnertq@gmail.com.

8 Universidade Federal do Espírito Santo, Brasil. E-mail: willian.fito@gmail.com.
} 